\title{
A literatura brasileira em tradução: o caso do Programa de Apoio à Tradução e à Publicação de Autores Brasileiros no Exterior
}

\section{Brazilian literature in translation: the case of the Support Program for Translation and Publication of Brazilian Authors Abroad}

\author{
Lilia Baranski Feres ${ }^{1}$, Valéria Silveira Brisolara²
}

Mestranda em Letras pelo UniRitter. Bolsista Fapergs/Capes. Autora do artigo "Reflexões sobre oxercicio autoral em duas traduções de The nightingale and the rose".

Doutora em Letras (UFRGS). Professora do Programa de Pós-graduação em Letras do UniRitter.

E-mail: valeria_brisolara@uniritter.edu.br
RESUMO: 0 processo tradutório configura-se por ser uma atividade que ocorre entre fronteiras, sendo a literatura brasileira inerentemente transnacional e transcultural. Entretanto, embora o português seja a sexta língua mais falada no globo, não faz parte das línguas mais traduzidas para o inglês. Ademais, aproximadamente $60 \%$ das publicações brasileiras são traduções, sendo a maioria (cerca de 75\%) oriunda do inglês. Assim, o tradutor é imprescin dível como porta-voz, conectando o Brasil ao mercado editorial mundial. Um maior interesse internacional na literatura brasileira pode ser observado pela culminância de eventos hodiernos: o lançamento, pelo governo federal, do Programa de Apoio à Tradução e à Publicação de Autores Brasileiros no Exterior, do Programa de Internacionalização do Livro e da Literatura Brasileira, a inserção do Brasil nas agendas culturais de âmbito literário e a publicação da versão em inglês da revista Granta em 2012 intitulada The best of young Brazilian novelists. Essas ações, que investem na tradução e na publicação de obras brasileiras nos Estados Unidos, no Reino Unido e nos demais países, vêm ao encontro dessa parca participação do Brasil no mercado literário mundial, surgindo como uma resposta a essa escassez. Partindo da leitura e análise de referencial teórico (HALL, 1995, 1997; MELLO, 2012; MELLO e VOLLET, 2000, etc.) e da revista literária Granta, este trabalho tem o intuito de refletir e discutir acerca da atual situação da literatura brasileira, no tocante às traduções e publicações de obras brasileiras através da concessão de auxílio por meio dos editais do Programa de Apoio à Tradução e à Publicação de Autores Brasileiros no Exterior, considerando a função que a tradução desempenha no reposicionamento da literatura brasileira no contexto global e o papel da revista Granta como ferramenta de autoridade nessa dinâmica.

Palavras-chave: Tradução; Literatura; Brasil.

ABSTRACT: The translation process is characterized for being an activity located between borders, making Brazilian literature inherently both transnational and transcultural. Nonetheless, despite the fact that Portuguese is the sixth most spoken language around the globe, it is not listed as one of the languages most translated into English. In addition to that, approximately $60 \%$ of what is published in Brazil are translations, being most of them (around 75\%) translated from English. Therefore, translators are indispensable in their role of spokesperson, connecting Brazil to the world publishing market. There has been an observable increase in the international interest for Brazilian literature, which can be noticed through the culmination of recent events: the launching, by Brazilian government, of the Support Program for Translation and Publication of Brazilian Authors Abroad; Support Program for the Internationalization of book and Brazilian literature; the insertion of Brazil in literary cultural agendas around 
the world; and the publishing of the English version of Granta literary magazine in 2012 entitled The best of young Brazilian novelists. Such actions, which invest in both translation and publication of Brazilian works in the United States, in the United Kingdom, as well as in other countries, come to meet this meager participation of Brazil in the global literary market, emerging as a response to this shortage. Based on the reading and analysis of theoretical background (HALL, 1995, 1997; MELLO, 2012; MELLO and VOLLET, 2000, etc.), and of Granta literary magazine, this paper aims at reflecting and discussing about the current situation of Brazilian literature, regarding translations and publications of Brazilian works through grants of the Support Program for Translation and Publication of Brazilian Authors Abroad, considering the role played by translation in the relocation of Brazilian literature in the global context as well as the role played by Granta as an authoritative tool in this dynamics.

KEYwoRDS: Translation; Literature; Brazil.

\section{Considerações iniciais ${ }^{1}$}

partir do momento em que informações concebidas em determinada língua e cultura são transportadas para língua e cultura diferentes, uma atividade transcultural se estabelece. Quando um romance escrito em francês é traduzido para o português, fronteiras linguísticas e culturais são trespassadas. Através dessas reescrituras, conhecimentos de uma cultura seja ela dominante/central ou não - rompem barreiras e ganham espaço. A tradução é, portanto, uma atividade que ocorre entre fronteiras, viabilizando à literatura seu caráter transnacional e transcultural ao passo que também permite que o leitor se depare com as distintas representações de identidades culturais (HALL, 2005) materializadas nas literaturas.

No entanto, pensando sobre a participação do Brasil nessas trocas de âmbito literário, percebemos que muito embora o português seja a sexta língua mais falada globalmente, não pertence aos idiomas mais traduzidos para o inglês. As obras dos países ditos de 'terceiro mundo' representam

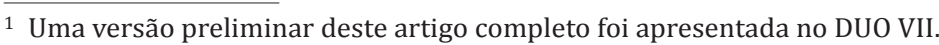

$1 \%$ ou $2 \%$ das traduções dos países ditos de 'primeiro mundo' e $60 \%$ das publicações ficcionais são traduções do inglês; dentre os best-sellers de ficção, há um autor nacional para dois autores estrangeiros (MELLO e VOLLET, 2000). No ano de 1990, apenas 2,4\% dos livros britânicos publicados e somente 2,9\% dos títulos americanos foram traduções. As discrepâncias apontadas pelas estatísticas corroboram o receio de Hall (1997, p. 4) em relação a uma possível "homogeneização cultural", embora saibamos que a forma como cada local reage ao global é única e imprevisível, resultando em dinâmicas heterogêneas. Ademais, Hall (1997, p. 4) também nos lembra que a distribuição da cultura não é igualitária. Está sempre em jogo o que o autor denomina "geometria do poder" (HALL, 1997, p. 4), que determina o quê, como, quando e quanto será enviado e recebido nas trocas interculturais, estabelecendo, assim, hegemonias e subordinações, interesses e omissões, dominações e exclusões.

Países com maiores índices no âmbito das traduções também revelam dados interessantes: há uma predominância de traduções de títulos em língua inglesa. Na França, em 1985, 71\% das versões provinham do inglês enquanto que na Alemanha, em 1990, aproximadamente 65\% eram oriundas 
da língua inglesa (VENUTI, 1995, p. 13,14). Segundo um estudo realizado para o relatório mundial da UNESCO sobre diversidade cultural (2009), $75 \%$ do total de livros cadastrados da ferramenta Index Translationum (1979-2007) foram traduzidos de apenas três línguas: inglês, francês e alemão. Como língua-fonte, o inglês sozinho é responsável por 55\% dos livros traduzidos em todos os gêneros. Outra estatística reveladora no tocante à assimetria desse tipo de troca cultural é que das cerca de 800 línguas identificadas no Index, vinte (das quais dezesseis tratam-se de línguas europeias) constituem-se como língua-fonte de 96\% dos livros traduzidos. A mesma disparidade pode ser observada no que se refere às línguas-alvo: 50\% dos livros registrados foram traduzidos para apenas cinco idiomas: alemão, espanhol, francês, inglês e japonês (BRISSET, 2011). Dados como os apresentados configuram evidências contundentes: o fato de que "a cultura dominada traduz incomparavelmente mais a cultura hegemônica do que vice-versa" (MELLO e VOLLET, 2000, p. 6). A tradução se apresenta, portanto, como um fenômeno (entre outros) prevalecente de atuação internacional nos mercados literário e editorial. A demanda por traduções cresceu exorbitantemente com o advento da globalização, entretanto, de modo paradoxal, mascara a diversidade cultural em virtude da hierarquia estabelecida pelos idiomas que participam dessa dinâmica. Um dos efeitos dessa equação desigual é que tanto a língua quanto a cultura dos países chamados de 'terceiro mundo' são rigorosamente afetadas pelas línguas e culturas dos países considerados de 'primeiro mundo'. Portanto, dentro da dinâmica de trocas interculturais, o Brasil apresentase como um país que mais importa do que exporta cultura, no que tange à literatura.

Em razão de problemáticas como as anteriormente citadas (entre muitas outras, evidentemente), faz-se mister abordar questões de tradução sob outro olhar. A atividade tradutória sempre foi e sempre será complexa, mas antigamente muito dessa complexidade era ignorada, tanto no sentido de ser desconhecida quanto no sentido de ser deixada de lado intencionalmente. Hoje, porém, é imprescindível que a tradução seja encarada como o fenômeno intricado que é, exigindo olhares que atentem para as relações que se estabelecem entre os diversos sistemas que compõem os grandes sistemas literário e cultural, levando em conta, portanto, aspectos sociológicos, políticos e ideológicos que atuam em tempo e espaço específicos.

O cenário complexo de problemas enfrentados nos campos literário e editorial, que se materializa na disparidade entre países hegemônicos e não hegemônicos, coaduna-se com iniciativas do governo federal que visam ao incremento das trocas interculturais entre o Brasil e o resto do mundo. Essas iniciativas vão ao encontro da constatação de que o Brasil tem vivenciado um acréscimo de notoriedade no palco internacional (FAVERI, 2015). De acordo com dados da Câmara Brasileira do Livro, a venda de direitos autorais para países estrangeiros teve um acréscimo de US\$ $495 \mathrm{mil}$ em 2010 para US\$ 1,2 milhão em 2012 (FERNANDES e FERNANDES, 2015, p. 87). Nos primeiros anos da década de 90 , após ter participado da feira de Frankfurt, nosso país teria observado um aumento substancial no número de traduções de suas obras (FAVERI, 2015, p. 2). É bem provável que novas iniciativas governamentais almejem ampliar os resultados obtidos nos anos 90. É o caso do Programa de Apoio à Tradução e à Publicação de Autores Brasileiros no Exterior, inserido no Programa de Internacionalização do Livro e da Literatura Brasileira. Tanto essas medidas quanto a publicação da revista literária inglesa Granta (2012) intitulada The best of young Brazilian novelists, vêm ao encontro da parca participação brasileira no mercado literário mundial, surgindo como resposta ao impasse dessa desigualdade no fluxo de trocas culturais da atualidade. 


\section{As iniciativas federais de incentivo à internacionalização da literatura brasileira}

O Programa de Internacionalização do Livro e da Literatura Brasileira, de responsabilidade da Fundação Biblioteca Nacional, juntamente com o Ministério da Cultura, consiste em uma agenda política governamental cujo próprio nome explicita seu objetivo primordial: disseminar mundo afora a literatura criada por escritores brasileiros. Há planejamento para que se invista $\mathrm{R} \$ 76$ milhões até 2020 . O programa se sustenta sobre alguns pilares, que na realidade constituem iniciativas menores e mais direcionadas a pontos específicos do programa maior. Entre eles estão: o Programa de Apoio à Publicação de Autores Brasileiros na Comunidade dos Países de Língua Portuguesa (CPLP), que consiste em bolsas para editoras dos paísesmembro da CPLP no valor de até R\$ 6 mil concedidas a interessados em adaptar textos brasileiros para as características do português falado em Portugal, em países africanos onde o português é a língua oficial (Angola, Cabo Verde, Guiné-Bissau, Moçambique, São Tomé e Príncipe) e no Timor Leste; o Programa de Residência de Tradutores Estrangeiros no Brasil, através do qual tradutores estrangeiros que estejam trabalhando na tradução de livros brasileiros podem se candidatar a bolsas no valor de até R \$ 15 mil, para residência de até cinco semanas²; o Programa de Intercâmbio de Autores Brasileiros no Exterior, que contempla editoras estrangeiras que promovam a literatura brasileira por meio de palestras, sessões de autógrafos e entrevistas - o edital estima o pagamento de Na primeira parte, os tradutores realizam uma imersão na cultura brasileira que supra as necessidades
específicas da obra a ser traduzida. Na segunda parte, os tradutores participam de oficinas e palestras
nas comunidades em que estiverem alojados e, também, em cursos ministrados em centros de estudos
de tradução que sejam parceiros do programa (como o da Universidade Federal Fluminense (UFF),
Casa Guilherme de Almeida, da Secretaria Estadual de Cultura de São Paulo, e a Universidade Federal de Santa Catarina (UFSC)). bolsas de até US\$ 3 mil; e o Programa de Apoio à Tradução e à Publicação de Autores Brasileiros no Exterior.

A última ação governamental mencionada, que está em foco neste trabalho, foi implementada pela Fundação Biblioteca Nacional, juntamente com o Ministério da Cultura, com o objetivo de "difundir a cultura e a literatura brasileiras no exterior" através do fornecimento de apoio financeiro a editoras estrangeiras que têm interesse em traduzir (para qualquer idioma), publicar e distribuir (em forma de livro impresso ou digital), no exterior, obras de escritores brasileiros que tenham sido previamente publicadas em português no Brasil. Em virtude de uma parceira feita com o Conselho Nacional de Desenvolvimento Científico e Tecnológico (CNPq), o programa pode apoiar tanto projetos de obras técnicas ou científicas nas áreas de Ciências Humanas e Sociais Aplicadas, Ciências da Vida, Engenharias, Ciências Exatas e da Terra quanto no campo da literatura, em especial os gêneros romance, conto, poesia, crônica, infantil e/ou juvenil, teatro, obra de referência, ensaio literário, ensaio de ciências sociais, ensaio histórico, ensaio de vulgarização científica e antologias de poemas e contos, integrais ou em parte. $O$ auxílio pode ser concedido a propostas de traduções inéditas, novas traduções ou reedições de obras já traduzidas no país e que tenham se esgotado ou estejam fora de mercado por no mínimo três anos. Há também a previsão de lançamento de editais específicos da Fundação Biblioteca Nacional para regiões e/ou idiomas particulares, e efemérides.

Foram concedidas 770 bolsas de apoio à tradução no período de 1991 a 2014 (que inclui a época quando o programa não era tão expressivo e não operava sob a atual alcunha), sendo que a iniciativa foi responsável pela concessão de 543 bolsas (70\% da totalidade) entre os anos de 2011 e 2014 (no ano de 2011, o programa anteriormente em vigor foi reformulado, renomeado e relançado), segundo dados fornecidos pelo Ministério da Cultura. A estimativa é de que os investimentos se estendam até o ano de 
2020. As bolsas concedidas às editoras internacionais podem chegar a $R \$$ 8 mil. Com base no fato de que 70\% dos incentivos concentram-se nos últimos quatro anos do programa de auxílio, percebe-se que essa medida do governo federal representou um incremento significativo no número de obras brasileiras a serem traduzidas para outros idiomas. Somente através do programa da Fundação Biblioteca Nacional, são 290 escritores brasileiros com publicações em 47 países.

Outra forma encontrada pelo Ministério da Cultura de intensificar a presença do Brasil no exterior foi através de uma maior participação de editoras nacionais em eventos internacionais. A Fundação Biblioteca Nacional investiu na elaboração de uma agenda (que também se estenderá até 2020) de inserção de nosso país em uma série de eventos literários de renome mundial: Feira do Livro de Frankfurt, em 1994 e 2013 (um dos dois únicos países a ser homenageado duas vezes; o outro é a China); Bienal Internacional do Livro do Rio de Janeiro, em 2011; Feira do Livro de Bogotá (como convidado de honra), em 2012; Feira do Livro de Bolonha, em 2014; Feira Internacional do Livro de Gotemburgo, em 2014; Feira do Livro de Caracas, em 2014; Salão do Livro de Paris, em 2015; Feira do Livro de Londres, em 2016; Feira do Livro de Nova York, em 2017; entre outros ainda não divulgados. Complementarmente, o Centro Internacional do Livro também participa, em associação com entidades do ramo, como a Câmara Brasileira do Livro (CBL), dos principais eventos da área, com o objetivo de intensificar a presença do Brasil nos anos subsequentes às homenagens. Todas essas medidas visam a despertar maior interesse das editoras internacionais pela literatura produzida no Brasil. E elas parecem estar de fato surtindo efeito, já que, segundo publicações de 2015 do Ministério da Cultura, percebeu-se uma alteração dos locais de chegada das traduções nos últimos dez anos. Leitores da França, Itália e Argentina representavam (e continuam sendo importantes importadores de nossas obras) os principais consumidores de literatura brasileira traduzida. Porém, a partir de 2010, a Alemanha passou a investir mais na tradução de obras brasileiras e hoje representa o maior consumidor

\section{Os resultados do Programa de Apoio à Tradução e à Publicação de Autores Brasileiros no Exterior}

A seguir, são apresentados dados referentes ao número de obras brasileiras traduzidas por países estrangeiros através do uso do auxílio governamental disponibilizado via editais do Programa de Apoio à Tradução e à Publicação de Autores Brasileiros no Exterior. As informações foram obtidas junto à Fundação Biblioteca Nacional por duas vias: $e$-mail e pedido de acesso à informação no Portal da Transparência - plataforma e-SIC (Sistema Eletrônico do Serviço de Informação ao Cidadão) ${ }^{3}$. Os números referem-se aos anos de 2010, 2011, 2012, 2013 e 2014.

Em uma análise mais detalhada dos dados disponíveis a partir de 2010, observa-se que, como nos mostra a figura 1 (Fig. 1), no ano de 2010, Argentina (com 3 títulos), França (com 2 títulos) e Itália (também com 2 obras) foram os países que mais publicaram livros brasileiros através das bolsas do Programa de Apoio à Tradução de Autores Brasileiros, embora os números não pareçam muito expressivos. Os dados corroboram a afirmação de que Argentina, França e Itália têm mais tradição como países importadores de literatura brasileira. Entretanto, os números sofrem algumas alterações nos anos seguintes. Apenas editoras de nove países candidataram-se ao/receberam o auxílio à tradução. É importante notar que não há nenhum país de língua inglesa na lista de 2010. E o total de livros traduzidos publicados nos 9 países foi de apenas 13. Faz-se mister salientar que os dados

As informaç̃es foram requeridas em dois momentos: em 06/06/2015 (protocolo $\mathrm{n}^{\circ}$ 01590000613201500) e em 14/06/2015 (protocolo no 01590000634201517). 
referem-se exclusivamente aos títulos brasileiros traduzidos e publicados por meio das bolsas do Programa de Apoio à Tradução e à Publicação de Autores Brasileiros no Exterior. Certamente, há diversas outras obras brasileiras sendo traduzidas e publicadas mundo afora por outras vias.

Figura 1 - Obras traduzidas em 2010 - Programa de Apoio à Tradução

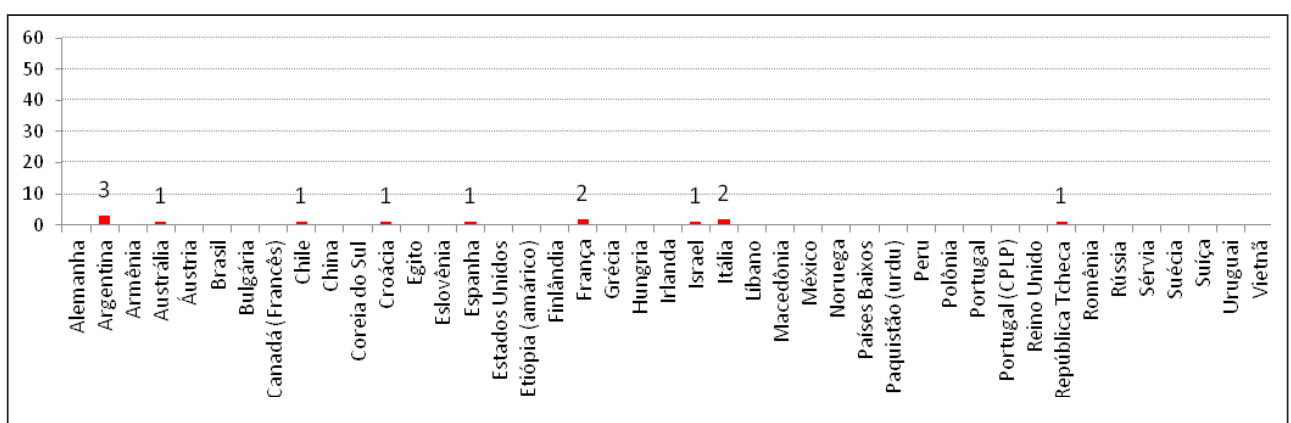

Em 2011 (Fig. 2), os países com maiores números de obras brasileiras traduzidas são, respectivamente: Argentina, com 8; Estados Unidos, Espanha e França, com 4 cada um. Embora haja um aumento significativo da participação dos Estados Unidos, o Reino Unido não publicou nenhuma obra brasileira traduzida no referido ano, o que poderia ser explicado pelo fato do Reino Unido mostrar-se mais conservador em comparação com o país norte-americano. Observa-se que, afora a estreia dos Estados Unidos, da Romênia, dos Países Baixos, entre outros menos expressivos, Argentina, França e Itália seguem com significativa atuação no que diz respeito à publicação de literatura brasileira. A Espanha também passa a integrar esse grupo. Os números, mesmo sutilmente, já mostram um número maior de editoras/países participantes no programa: foram 12 no total, contra 9 no ano anterior. De igual forma, houve um ligeiro acréscimo na soma de livros: foram 31, contra 13 em 2010 - aumento de 138\%.
Figura 2 - Obras traduzidas em 2011 - Programa de Apoio à Tradução

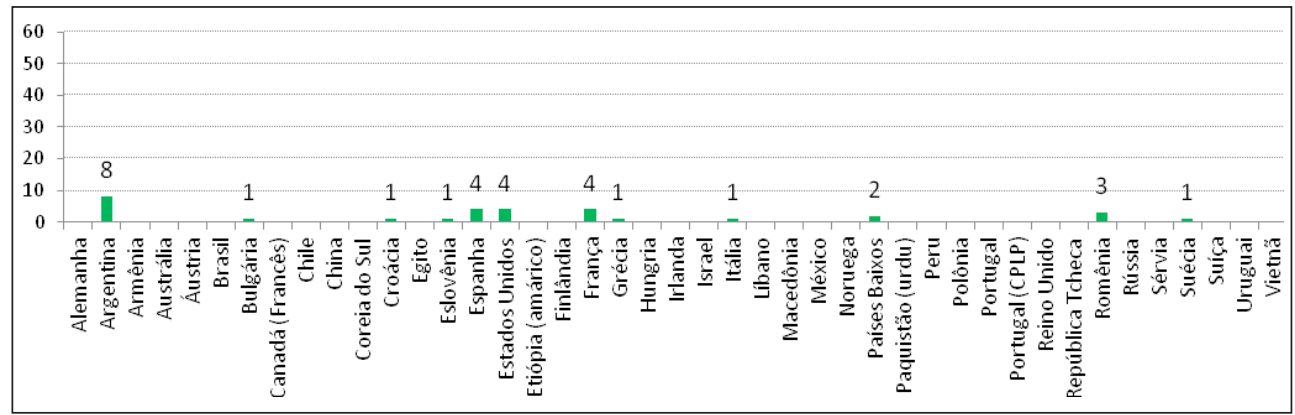

Um grande salto ocorre no ano de 2012 (Fig. 3), quando o número de países participantes duplica. Há 24 - um aumento de 50\% - países cujas editoras estão recebendo apoio à tradução e um total de 79 títulos aumento de aproximadamente $155 \%$ - traduzidos publicados. As nações mais expressivas são Espanha (com 9 títulos, incluindo os publicados em Catalão); Romênia (com 8); Brasil (com 7) ${ }^{4}$; França, Reino Unido e Itália (com 6 cada país). Novamente, vemos a permanência de França, Itália, Espanha e Argentina com números significativos. A aparição inaugural do Reino Unido (6 títulos), inclusive superando os Estados Unidos (4 títulos) poderia ter sido incentivada pela presença vanguardista, no ano anterior, do país norte-americano que, após disponibilizar obras brasileiras traduzidas para a língua inglesa, pode ter despertado maior interesse de outros falantes do mesmo idioma, no caso o Reino Unido. Neste ano, há também a estreia da Alemanha no programa (5 obras), que irá intensificar sua participação no ano subsequente, e de outros países como Irlanda, Peru, Chile, China, Hungria, México e Sérvia. Há, ainda, a participação de Portugal (3 títulos), dentro do Programa de Apoio à Publicação de Autores Brasileiros na Comunidade dos

${ }_{4}^{4}$ Tratam-se de obras brasileiras publicadas no Brasil em idioma diferente do português. 
Países de Língua Portuguesa (CPLP), concedido a interessados a adaptar textos brasileiros para o português falado em Portugal, em determinados países africanos e no Timor Leste.

Figura 3 - Obras traduzidas em 2012 - Programa de Apoio à Tradução

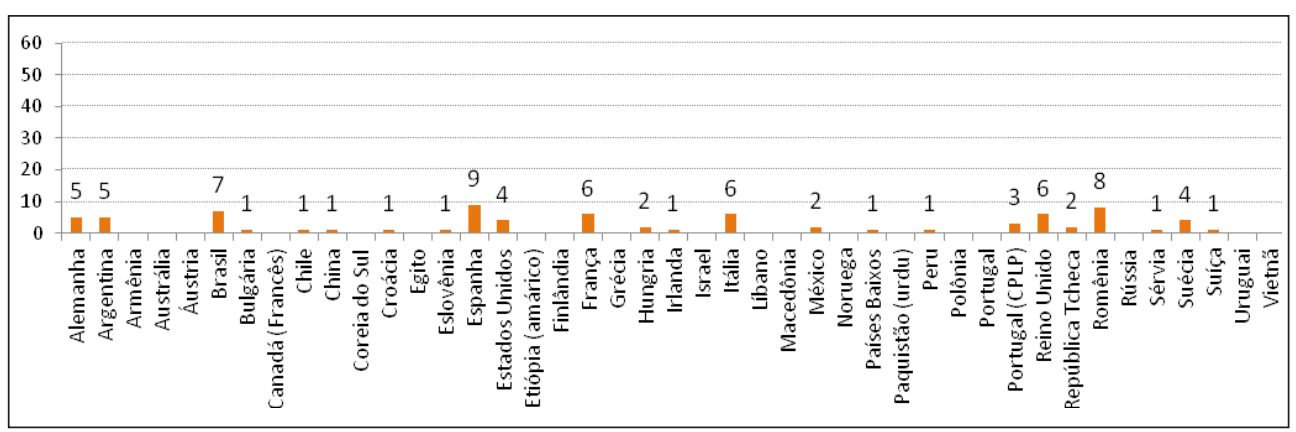

O que fora dito anteriormente, sobre a Alemanha ser um país que muito consome literatura brasileira, é corroborado pelos expressivos números referentes aos títulos que receberam bolsas de apoio à tradução em 2013 (Fig. 4). Foram 59 livros (alguns no formato e-book) publicados em apenas um ano, ou seja, um aumento de $1.080 \%$ em relação ao ano anterior. 0 segundo colocado da lista, a Espanha, conta com 18 livros. Trata-se de uma discrepância substancial. Os próximos países são Itália (com 15), Argentina (com 15) e França (com 12), que perderam a liderança de 2010. Mais uma vez, excetuando o desempenho desproporcional do país germânico, Argentina, Espanha, França e Itália seguem fortes como o grupo de países que mais traduzem nossa literatura. Os Estados Unidos (10 obras) voltam a superar o Reino Unido (6 obras) e a Romênia se mantém relativamente estável com um número razoável de publicações. Países como Polônia, Noruega e Líbano fazem sua estreia. No ano em questão, o número de países participantes subiu ainda mais, totalizando 30 e, obviamente, devido ao impacto da atuação da
Alemanha, a soma de todos os livros disparou, alcançando a marca de 193, o que representa um aumento de $144,3 \%$ em relação a 2012. É importante relembrar que em 2013 o Brasil foi o país homenageado na Feira do Livro de Frankfurt. É possível, portanto, que a robusta participação da Alemanha, com um total de 59 livros brasileiros publicados (em comparação com o segundo colocado - Argentina - com 15 obras), seja um reflexo do grande enfoque dado ao nosso país no evento literário internacional alemão, considerado o de maior porte nesse âmbito. Nesse sentido, fica evidente que iniciativas desse tipo são eficazes e trazem resultados imediatos.

Figura 4 - Obras traduzidas em 2013 - Programa de Apoio à Tradução

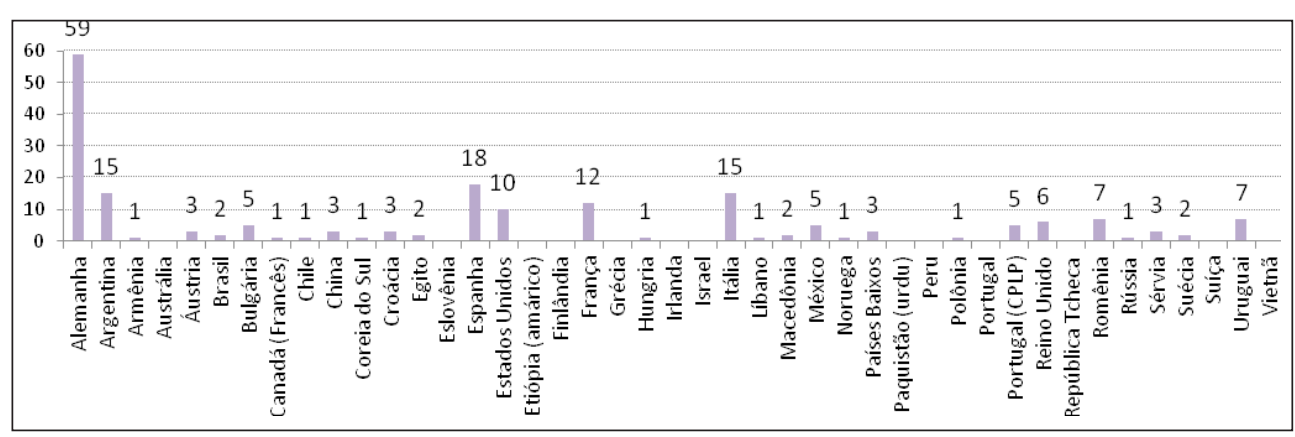

Já no ano de 2014 (Fig. 5), os números decresceram, principalmente no tocante à quantidade de livros. Foram 28 países e um total de 123 obras traduzidas publicadas. Desta vez é a França quem lidera, saltando de 12 (em 2013) para 21 livros, seguida da Espanha e da Itália, cada uma com 14 títulos. Surpreendentemente, a Alemanha, que havia sido a recordista no ano anterior, nem consta na listagem de 2014, ou seja, editoras do país ou não se candidataram para o incentivo ou não receberam nenhuma bolsa de apoio à tradução. Novamente, França, Espanha, Itália e Argentina figuram como países com tradição na tradução e publicação de obras brasileiras, 
Figura 5 - Obras traduzidas em 2014 - Programa de Apoio à Tradução

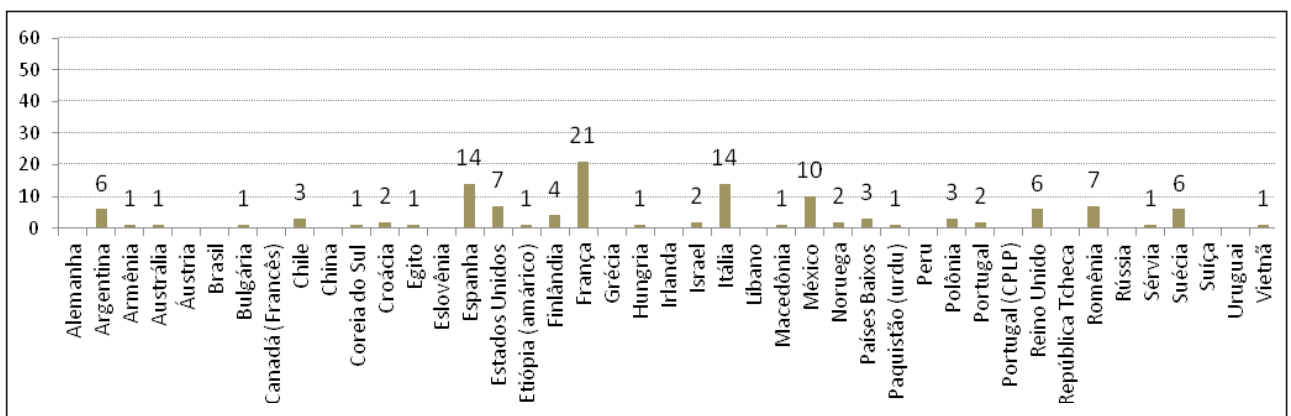

embora a participação da Argentina tenha caído significativamente. Estados Unidos (7 livros) e Reino Unido (6 livros) mostram-se equiparados em 2014 e seguindo o mesmo padrão de índices não muito elevados de publicação de obras brasileiras em língua inglesa. Tais informações vão ao encontro da teorização de Venuti (1995). Segundo o autor, editoras inglesas e americanas participam de feiras internacionais de livros e lá vendem os direitos de tradução de diversos títulos em língua inglesa, principalmente best-sellers. A contrapartida, entretanto, não é equilibrada. O mercado americano "raramente compra os direitos para publicar traduções em língua inglesa de livros estrangeiros"5 (VENUTI, 1995, p. 14). Pelos dados do Programa de Apoio à Tradução e à Publicação de Autores Brasileiros no Exterior, esses dois países, mesmo com a oportunidade de concessão de bolsas, parecem ter pouco interesse em disseminar a literatura brasileira por meio de traduções subsidiadas pelo nosso governo federal. Paquistão e Vietnã fazem sua estreia no programa. É possível observar que a Suécia, embora não apresente altos índices de participação, mostrou um aumento três vezes maios em relação

\footnotetext{
Tradução da autora. Citação original: "rarely buy the rights to publish English-language translations of foreign books" (VENUTI, 1995, p.14)
}

ao ano anterior. Mais uma vez, tal qual ocorreu com a Alemanha (após o Brasil ter figurado como país homenageado na Feira de Frankfurt em 2013), é possível que esse acréscimo seja resultado da participação do Brasil como país destaque na Feira Internacional do Livro de Gotemburgo em 2014. Outra vez, uma medida estratégica parece ter cumprido seu objetivo, mesmo que de forma modesta.

\section{A revista literária Granta e a divulgação de literatura brasileira}

Dentre as 6 obras brasileiras traduzidas no Reino Unido em 2012 está a edição 121 da revista literária Granta, cujo título é The best of young Brazilian novelists. A revista em questão foi criada em 1889 por alunos da Universidade de Cambridge e nomeada Granta em homenagem ao rio que cruza a cidade. Originalmente, servia como veículo de notícias e chistes estudantis, mas quase cem anos após sua criação (em 1979), sofreu uma grande reformulação e ganhou formato de revista literária trimestral. Um pouco mais tarde, foram lançados os livros com selo Granta, que rapidamente adquiriram status e prestígio, contribuindo para a sua consolidação como editora literária independente. As edições da revista com os títulos do tipo "Os melhores jovens escritores [...]", publicadas a cada dez anos, se propõem a apresentar os mais importantes nomes de cada geração. Foram lançados títulos referentes aos melhores jovens escritores da Inglaterra, da América (do Norte), do Brasil e da Espanha. A revista defende que suas edições têm "definido os contornos do cenário literário desde 1983"6, embora alegue "não ter uma agenda política ou literária".

6 Tradução da autora. Citação original: "defining the contours of the literary landscape since 1983" (<http://granta.com/about/> Acesso em: 02 jul. 2015). 
A edição sobre "os melhores jovens escritores brasileiros" foi primeiramente lançada em português (Granta v. 9) e posteriormente lançada em versão inglesa (Granta v. 121), através do Programa de Apoio à Tradução e à Publicação de Autores Brasileiros no Exterior. Para a elaboração da edição em português foram escolhidos vinte autores, todos nascidos depois de 1972, que por meio de sua escrita "contribuem para mudar o panorama das letras no país" (GRANTA EM PORTUGUÊS, 2012, p. 5). Os textos brasileiros compilados retratariam uma parcela significativa dos escritores em atividade no Brasil. Todos eles têm idade inferior a 40 anos e possuem no mínimo um conto publicado. A totalidade dos contos brasileiros compilados foi selecionada por um júri que acredita que "os textos compõem um mosaico surpreendente de estilos e temas e chama a atenção pelo vigor e apuro estilístico - o acerto nos detalhes, a busca por uma linguagem coesa, o desenvolvimento cuidadoso de personagens" (p. 6). O comitê julgador, nas palavras da revista, foi composto por "uma equipe de jurados altamente qualificada, editorialmente independente" (GRANTA EM PORTUGUÊS, 2012, p. 8) que contou com "pessoas de diferentes áreas da cena literária” (p. 8). Foram sete jurados: Beatriz Bracher, Cristovão Tezza, Samuel Titan, Manuel da Costa Pinto, Italo Moriconi, Marcelo Ferroni e Benjamin Moser, o único estrangeiro, (nome sugerido pela Granta inglesa), norte-americano, biógrafo de Clarice Lispector, tradutor e escritor. A revista alega que a presença de um jurado estrangeiro "enriqueceu o processo de escolha dos autores", com sua "visão 'externa"' (p. 9). Como justificativa para esse olhar alheio ao Brasil estar mais atento à literatura emergente desse país, a revista defende que "o Brasil vive um momento especial na literatura" (p. 9). É enfatizado o fato de que nos últimos vinte anos houve poucos escritores publicados e aclamados no cenário exterior. Inúmeros fatores estariam contribuindo para uma mudança desse cenário de baixa contribuição dos escritores brasileiros na literatura global. Entre eles, programas mais consistentes e duradouros de apoio à tradução e ao intercâmbio de agentes do campo literário, um aumento do interesse de editoras e agentes estrangeiros por escritores de língua portuguesa e o Brasil como país homenageado em diferentes eventos literários ao redor do mundo 7 . Conforme dados mostrados até aqui, essa última medida federal parece dar resultados imediatos. É importante que haja iniciativas que se mostrem eficazes também a longo prazo e que se atente para os próximos desdobramentos dos atuais programas para investigar se de fato cumprem seus propósitos.

Em relação à publicação da edição inglesa da revista literária Granta, excluindo a questão da autoridade desempenhada por ela através de um discurso que dissemina opiniões sobre o que é bom ou não e sobre o que merece ser lido ou não, o veículo cumpre o papel de levar a outros países uma amostra dos trabalhos feitos por autores brasileiros. Desconsiderando o fato de esses vinte nomes serem ou não "os melhores" de sua geração, o importante é que há literatura brasileira sendo divulgada em outros países. Além disso, por a Granta gozar de status privilegiado no cenário literário mundial é bastante provável que seu discurso ecoe e repercuta em um interesse maior pelos vinte nomes elencados; em última análise, para fins deste trabalho, em um interesse maior pela literatura brasileira.

\section{Considerações finais}

Pesquisas nos mostram que, tradicionalmente, as obras brasileiras têm pouca representatividade no cenário literário mundial, principalmente no norte-americano (FERNANDES e FERNANDES, 2015; FAVERI, 2015). Os dados encontrados corroboram a teoria de Even-Zohar (1990), que defende que países detentores de uma literatura nacional forte e bem estabelecida

7 A agenda na qual o Brasil está inserido até 2020 foi citada anteriormente. 
tendem a ter na atividade tradutória um papel mais marginal, como é o caso dos Estados Unidos. Embora a parca participação da literatura brasileira no sistema literário traduzido norte-americano seja representada por certa variação de autores e gêneros literários, sendo Paulo Coelho, Jorge Amado, Clarice Lispector e Machado de Assis os recordistas de publicações no período 2000-2014, é possível observar um acréscimo no número de traduções de escritores contemporâneos, como João Paulo Cuenca e Milton Hatoum (FERNANDES e FERNANDES, 2015). Tais informações parecem ser indícios de um aumento do interesse por escritores menos prestigiados pelo público e pela crítica (pelo menos atualmente) e da importância de se investir em diferentes formas de inserção dos autores brasileiros no cenário literário internacional.

A evolução do número de obras brasileiras traduzidas no exterior com auxílio de verba federal (Fig. 6) nos mostra que a participação do Brasil no cenário internacional vem aumentando nos últimos anos. A leve queda observável em 2014 se justifica, em grande parte, pela ausência da Alemanha, que havia traduzido um total de 59 livros no ano anterior. Entretanto, a linha de tendência nos mostra que é possível esperar um acréscimo do número de obras a serem traduzidas e publicadas nos próximos anos.

Figura 6 - Evolução das obras traduzidas - Programa de Apoio à Tradução

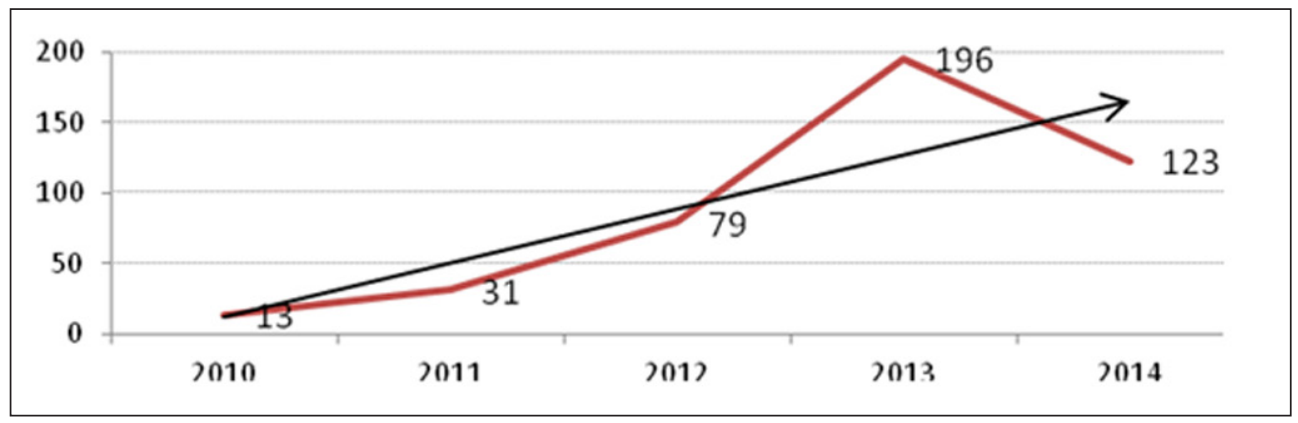

As iniciativas do governo federal, juntamente com a publicação da revista literária Granta (tanto em português quanto em inglês), podem, sim, ser ferramentas relevantes para atrair mais atenção para o que é produzido no Brasil (em termos literários, já que, no quesito música, parecemos ter bastante atenção do público externo). Os dados sugerem, de fato, que o Brasil tem caminhado em direção a um maior reconhecimento internacional de seus escritores e de sua literatura. No que tange às traduções para países de língua inglesa, percebe-se que, desde 2010, houve um suave acréscimo na publicação de obras brasileiras com o auxílio do programa federal de incentivo. $\mathrm{O}$ assunto, entretanto, não deve ser tratado com ingenuidade. Devemos ter consciência de que somente medidas governamentais são insuficientes para solucionar o dilema da disparidade existente nas trocas culturais entre esses países de língua inglesa e o Brasil (e a maioria dos demais países). Há muitos outros fatores presentes nas dinâmicas do sistema literário, que regem o estabelecimento de padrões hegemônicos e que fogem do alcance de medidas desse tipo. Entretanto, os resultados encontrados corroboram a importância de se investir em medidas de disseminação e internacionalização na literatura brasileira, seja através da concessão de bolsas de apoio, da publicação de edições de revistas literárias dedicadas a apresentar a literatura que está sendo produzida recentemente por nossos autores ou da inserção de nosso país nas agendas culturais mundo afora. Mesmo que tais investimentos pareçam não estar mudando definitivamente o cenário literário mundial, grandes mudanças só podem ser obtidas através dos primeiros passos dados.

Para fins deste trabalho, o foco manteve-se nos dados quantitativos, pois a intenção era investigar se as medidas propostas pelo governo federal estão de fato sendo eficazes no sentido de aumentar a divulgação da literatura brasileira no exterior. Por isso, somente o total de livros traduzidos nos anos analisados serviu como base para a pesquisa. Entretanto, também é 
de vital importância analisar quais os títulos que estão sendo importados pelas editoras participantes do Programa de Apoio, pois tais informações podem nos oferecer pistas sobre o tipo de literatura que tem chamado mais atenção dessas editoras e desses países e os desdobramentos acarretados pelas decisões editoriais. Este assunto, de igual relevância, será foco de estudos posteriores.

\section{Referências}

BRISSET, Annie. Cultural perspectives on translation. Trad. Marcos Bagno. International Social Science Journal, UNESCO, mar. 2010, v. 61, n. 199, p. 69-81, out. 2011.

EVEN-ZOHAR, Itamar. Polysystem studies. Poetics today. Durham: Duke University Press, v. 11, n. 1, 1990.

FAVERI, Claudia Borges de. $O$ Brasil traduzido: palavra estrangeira. São Paulo: Rafael Copetti, 2015

FERNANDES, Sarah; FERNANDES, Thaís. Os Estados Unidos da América traduzem o Brasil: uma análise da última década. In: de FAVERI, Claudia Borges (Org.). O Brasil traduzido: palavra estrangeira. São Paulo: Rafael Copetti, 2015. p. 87-100.

FUNDAÇÃO BIBLIOTECA NACIONAL. [s.d.]. Carta de serviços ao cidadão. Disponível em: <www.bn.br/sites/default/files/documentos/diversos/2014/1115-institucional/ institucional-786.pdf >. Acesso em: 06 ago. 2015.

GRANTA. [s.d.]. About. Disponível em: <granta.com/about/>. Acesso em: 2 jul. 2015.

GRANTA EM PORTUGUÊS, 9: Os melhores jovens escritores brasileiros. Rio de Janeiro: Objetiva, 2012.

GRANTA, 121: The best of young Brazilian novelists. Granta: London, 2012.

HALL, Stuart. A centralidade da cultura: notas sobre as revoluções culturais do nosso tempo. Educação \& Realidade, Porto Alegre: Faculdade de Educação da UFRGS, v. 22, n. 2, jul./dez. 1997.

HALL, Stuart. A identidade cultural na pós-modernidade. Rio de Janeiro: DP\&A, 2005.

MELLO, Gustavo. Desafios para o setor editorial brasileiro de livros na era digital. [s.d].
BNDS Setorial. Brasília, n. 36. p. 429-473, 2012. Disponível em: <web.bndes.gov.br/bib/ jspui/bitstream/1408/1486/1/A\%20set.36_Desafios\%20para\%20o\%20setor\%20 editorial\%20brasileiro\%20de\%20livros\%20na\%20era\%20digital_P.pdf>. Acesso em: 19 maio 2015

MELLO, Giana Giani de; VOLLET, Neuza Lopes Ribeiro. A ética e o pós-colonialismo: uma prática de tradução. Alfa, São Paulo, 44 (n. esp.), p. 169-178, 2000.

MINISTÉRIO DA CULTURA. 15 jun. 2015. Lançado edital para tradução de autores brasileiros. Disponível em: <www.cultura.gov.br/noticias-destaques/-/asset_publisher/ OiKX3xlR9iTn/content/id/1270586>. Acesso em: 06 ago. 2015.

PORTAL BRASIL. 28 jul 2014. Governo lança na Flip programas para internacionalizar literatura brasileira. Disponível em: <www.brasil.gov.br/cultura/2012/07/governolanca-na-flip-programas-para-internacionalizar-literatura-brasileira>. Acesso em: 06 ago. 2015.

PROGRAMA DE APOIO À TRADUÇÃO E À PUBLICAÇÃO DE AUTORES BRASILEIROS NO EXTERIOR. Brazil: Literature Translation Grant. Centro de cooperação e difusão Fundação Biblioteca Nacional. 11 set. 2012. Ministério da cultura investirá US\$35 milhões na internacionalização da literatura brasileira até 2020. Disponível em: <bookcenterbrazil. wordpress.com/2012/09/11/in-egestas-mauris-et-erat-sed/>. Acesso em: 06 ago. 2015

VENUTI, Lawrence. The translator's invisibility: a history of translation. London and New York: Routledge, 1995. http://dx.doi.org/10.4324/9780203360064

Recebido em 09/11/2015.

Aceito em 16/08/2016. 